\title{
Intercellular communication of notochord cells during their differentiation in Cynops orientalis
}

\author{
ZENG $\mathrm{M}_{\text {IBAI }}\left(\mathrm{TSENG} \mathrm{M}_{\text {IPAI }}\right), \mathrm{Y}_{\mathrm{ING}}$ WANG . \\ Shanghai Institute of Cell Biology, Academia Sinica, \\ shanghai 200031, China.
}

\section{ABSTRACT}

Intercellular communication of notochord cells during their differentiation was studied by microinjection of a fluorescent dye, Lucifer Yellow. Close correlation existed between the incidences of dye coupling and quantitative evaluation of gap junctions. High incidences of dye coupling and of gap junctions occurred at a stage when notochord cells were active in the change of cell shape and cell arrangement. With the subsidence of cell movements, both dye coupling and gap junctions were reduced to lower levels. It was, therefore, suggested that intercellular communication via gap junctions played an important role in the coordination of notochord cell movements.

Gap junctions of altered configuration occurred in notochord cells in late tailbud stage. The comparison of incidences of dye coupling at this stage with those at other stages strongly suggested that the gap junctions of altered configuration functioned just as those of generalized type.

Key words: intercellular communication, gap junction, notochord cell.

\section{INTRODUCTION}

By morphometric analysis of freeze-etching replicas, it has been demonstrated that the ratio of the area of gap junctions to the total membrane changed during the development of notochord cells[1]. At late gastrula the ratio is 0.054 ; during the stages of neurulation it increased and remained high (0.106-0.181); and during the stages from tailbud to tadpole the ratio decreased and dropped drastically to 0.001 . All the gap junctions observed during the stages from late gastrula to early tailbud 
were of the generalized configuration by which gap junctions are recognized. However, during the tailbud and tadpole stages, besides the gap junctions of generalized configuration, gap junctions of altered configuration appeared[1].

To correlate the stages of development with changes of gap junctions and the intercellular communication might yield deeper insight into the role they played during different developmental stages. Moreover, it could be interesting to find out whether the gap junctions of altered configuration functioned just as those of the generalized type.

\section{MATERIAL AND METHODS}

Embryos of Cynops orientalis, a species of Chinese newt, were used. Naturally laid eggs were collected and reared at $20 \pm 1{ }^{\circ} \mathrm{C}$. Notochord cells of 5 stages of development were chosen. Mid-neurula and late neurula are 2 stages of neurula during which changes of cell shape and cell movement are very active[2]. The other three are early and late tailbud, and early tadpole stage when the notochord sheath has become thickened and reinforced and the vacuoles within the cells are being enlarbged[3]. The neuroepithelium of early neurula and the neural tube with the epithelium on the dorsal side of the embryo in later stages were carefully peeled off to expose the notochord. The trunk region of all stages was selected as the site for microinjection.

The cell to cell communication was analyzed by microinjection of a low molecular weight fluorescent probe, Lucifer Yellow CH (lithium salt, Sigma) and transfer of the dye into adjacent cells was examined and recorded, according to the method originally introduced by Stewart[4] now generally known as assay of dye coupling. The microinjection was performed under nitrogen gas pressure using a 5242 Eppendorf microinjector. An aqueous solution of 2-3 \% Lucifer Yellow was used. To determine the level of intercellular communication in each of the above mentioned stages, at least 20 or more cells were microinjected. Fluorescence images of probe distribution were taken 5-10 minutes after microinjection under an Opton Microscope using a HBO 50 mercury lamp with standard excitation filters. Micrographs were taken with 400 ASA Kodak film.

\section{RESULTS AND DISCUSSION}

Among the 5 stages examined, the incidences of dye coupling varied (Tab 1). For the 2 stages of neurula the incidence was high. Dye transfer was identified in $86 \%$ and $94 \%$ of the cases (with only $14 \%$ and 6\% non-transfer) respectively. As shown in Fig 1-2, the notochord cells of mid-neurula were polygonal in shape and closely adherent to each other. The dye injected into one cell spread to its neighbouring cells with ease. The incidence of dye coupling of the 2 tailbud stages was much lower than that of neurula stages. Notochord of tailbud assumed a rod-like structure with the characteristic arrangement of cells as a pile of coins. Incidences of dye transfer were 32 and $34 \%$. The dye was transferred from the injected cell to the neighbouring stack of cells with reduced fluorescence (Fig 3-4). In the majority of cases (68\% and 66\%) the dye remained in the cell injected (Fig 5-6). It was found that in early tadpole stage microinjection was very difficult to be carried out. The thickened sheath and the increased hydrostatic pressure of notochord cells at this stage[3] caused the handicap. Although 18 microinjections were carried out, but only in 6 of them dye was successfully injected into the notochord cells and all of them were non-transfers 

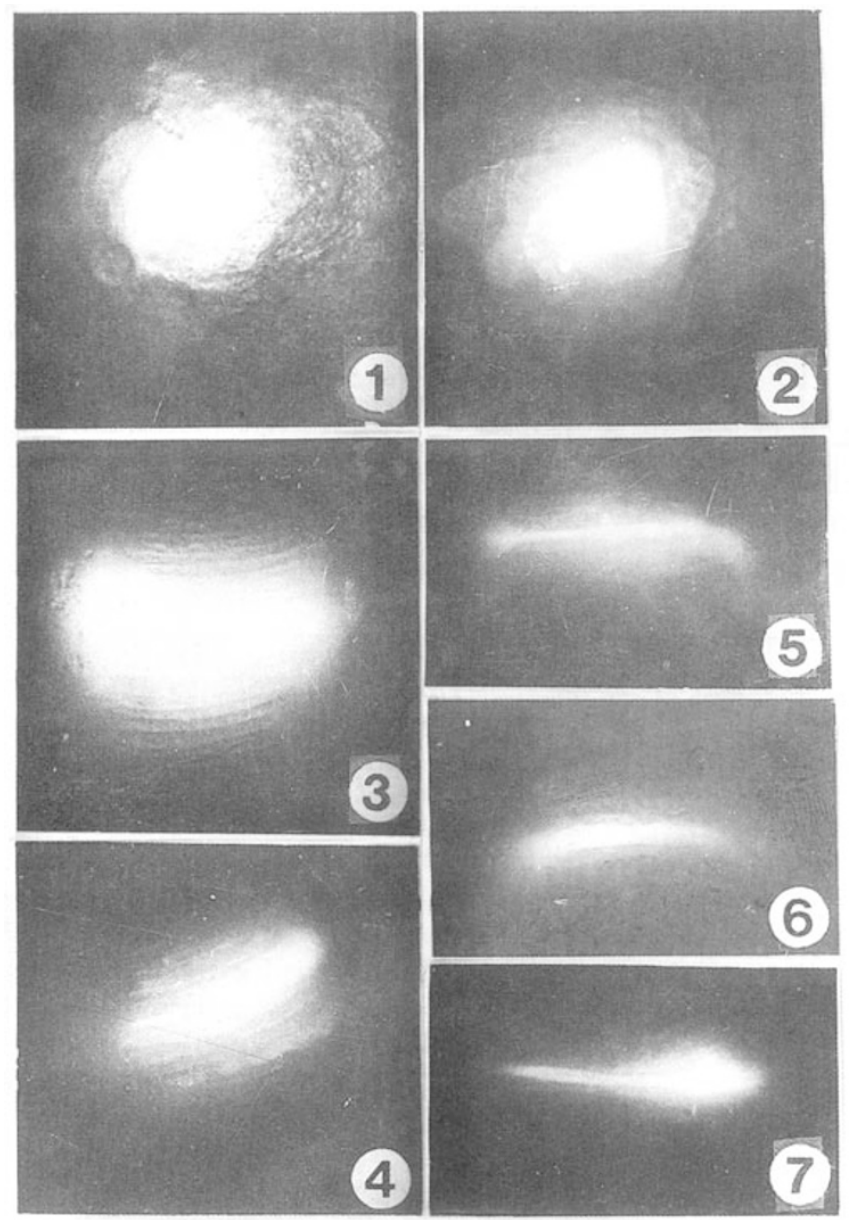

Fig 1-7. Dye coupling with Lucifer Yellow injection. All figures are enlarged to the same magnification: $\times 560$

Fig 1-2. Fluorescence image of notochord of midneurula injected with Lucifer Yellow into one cell and the dye spread to all its neighbouring cells.

Fig 3-4. Fluorescence images of notochord of late tailbud showing the dye transferred to cells above and below the injected cell.

Fig 5-7. Fluorescence images of notochord of early tailbud (Fig 5), late tailbud (Fig 6) and early tadpole (Fig 7) showing dye remained in the cell injected.

\section{(Fig 7).}

In order to clarify more about the significance of dye coupling, it was necessary to refer to the quantitative evaluations of gap junctions. The incidences of gap junctions of notochord cells at different developmental stages were listed in Tab.2, being taken and rearranged from our previous work[1]. The ratios of areas of gap junctions to total membrane of the 5 developmental stages were compared. At the first three stages, gap junctions identified were all of generalized configuration, and ratios were $0.146,0.167$ and 0.038 respectively. At late tailbud and early tadpole, besides gap junctions of the generalized configuration, gap junctions of altered configuration were also observed. When gap junctions of 2 different configurations were considered together, the ratios were 0.032 and 0.004 respectively.

When the results of dye coupling (Tab 1) were scrutinized with the respective incidence of gap junctions (Tab 2), it became evident that a very close correlation exists between the incidences of dye coupling and the results of quantitative evaluation 
Intercellular communication of notochord cells

Tab 1. Incidences of dye coupling in notochord cells

\begin{tabular}{lccc}
\hline $\begin{array}{l}\text { Embryonic } \\
\text { stages }\end{array}$ & $\begin{array}{c}\text { Number of } \\
\text { cells injected }\end{array}$ & Transfers & Nontransfers \\
\hline Mid-neurula & 21 & $18(86 \%)$ & $3(14 \%)$ \\
Late neurula & 33 & $31(94 \%)$ & $2(6 \%)$ \\
Early tailbud & 22 & $7(32 \%)$ & $15(68 \%)$ \\
Late tailbud & 41 & $14(34 \%)$ & $27(66 \%)$ \\
Early tadpole* & & & \\
\hline
\end{tabular}

* Refer to text

Tab 2. Gap junctions in notochord cells at different embryonic stages*

\begin{tabular}{|c|c|c|c|c|}
\hline \multirow{2}{*}{$\begin{array}{l}\text { Embrynic } \\
\text { stages }\end{array}$} & \multirow{2}{*}{$\begin{array}{c}\text { Area of } \\
\text { lateral } \\
\text { membrane } \\
\left(\mu \mathrm{m}^{2}\right)\end{array}$} & \multicolumn{2}{|c|}{ Area of gap junctuons $\left(\mu \mathrm{m}^{2}\right)$} & \multirow{2}{*}{$\begin{array}{c}\text { ratio of } \\
\text { junctions } \\
\text { to membrane } \\
\text { area }\end{array}$} \\
\hline & & $\begin{array}{c}\text { with only } \\
\text { generalized } \\
\text { configuration }\end{array}$ & $\begin{array}{l}\text { with both general- } \\
\text { ized and altered } \\
\text { configuration }\end{array}$ & \\
\hline Mid-neurula & 4382 & 6.41 & & 0.146 \\
\hline Late neurula & 2543 & 4.24 & & 0.167 \\
\hline Early tailbud & 1199 & 0.45 & & 0.038 \\
\hline Late tailbud & 2268 & 0.24 & $0.24+0.49$ & 0.032 \\
\hline Early tadpole & 1790 & 0.06 & $0.06+0.02$ & 0.004 \\
\hline
\end{tabular}

* Date taken from [1] and rearranged.

of gap junctions. The incidences of dye coupling attained a high level at 2 stages of neurula while ratios of the areas of gap junctions to the total lateral membrane were also elevated. The high incidences of both dye coupling and gap junctions appeared during the stages when notochord cells were very active in the change of cell shape and of cell arrangement. On the other hand, the incidences of dye coupling at 2 tailbud stages were markedly decreased just as those of gap junctions. After the completion of neurulation at tailbud stages active cell movements subsided. The parallelism of the rise and the fall of incidences of dye coupling and gap junctions with high motility and subsidence of cell movements did not seem to be circumstantial. Thus, it was suggested that the intercellular communication via gap junction may play an important role in the coordination of notochord cell movements.

Among the 4 stages at which microinjections had been successfully performed and incidences of dye coupling recorded, late tailbud stage in particular attracted our attention (Refer to Tab 2). This was one of the stages when gap junctions of both generalized configuration (A) and altered configuration (A') appeared. On the 
$2268 \mu \mathrm{m}^{2}$ lateral membrane, the combined area of A and A' was $0.73 \mu \mathrm{m}^{2}(0.24+$ 0.49). The ratio of area of gap junctions of generalized configuration to the total lateral membrane was only 0.011 , but when the areas of both types of gap junctions were considered together, the ratio reached 0.032 , a figure very close to that of the early tailbud stage ( 0.038 , Tab 2$)$ with only gap junctions of generalized configuration. The incidences of dye coupling at these 2 stages as recorded in Tab 1 were similar. Comparison of the incidences at this stage with those at other stages strongly suggested that gap junctions of both configurations functioned alike in the transfer of dye and probably played the same role in intercellular communication of embryonic cells. Although gap junctions of the type of altered configuration have been reported in cells of various embryonic tissues[5-7], this appeared to be the first report concerning the possible function of gap junction of altered configuration in intercellular communication as assayed by dye coupling.

\section{REFERENCES}

[1] Zeng Mi-bai, Zhou Mei-yun. A quantitative evaluation of gap junctions and their morphological alteration during differentiation of amphibian notochord cells. Roux's Arch Dev Biol 1992; 201:18-29.

[2] Keller R, Cooper MS, Danilchik M, Tibbetts P, Wilson PA. Cell intercalation during notochord development in Xenopas laevis. J Exp Zool 1989; 251:134-54.

[3] Adams DS, Keller R, Koehl MAR. The mechanics of notochord elongation, straightening and stiffening in the embryo of Xenopus laevis. Development 1990; 110:115-30.

[4] Stewart WW. Functional connections between cells as revealed by dye-coupling with a highly fluorescent naphthalimide tracer. Cell 1978; 14:741-59.

[5] Albertini DF, Andersen E. The appearance and structure of intercellular connections during the ontogeny of the rabbit ovarian follicle with particular reference to gap junctions. J Cell Biol 1974; 63:234-50.

[6] Ginzberg RD, Gilula NB. Modulation of cell junctions during differentiation of chicken otocyst sensory epithelium. Dev Biol 1979; 68:110-29.

[7] Shibata Y, Nakata K, Page E. Ultrastructural changes during development of gap junctions in rabbit left ventricular myocardial cells. J Ult Res 1980; 71:258-71.

Received 2-11-1992. Revised 2-3-1993. Accepted 2-3-1993. 